RESEARCH HIGHLIGHTS

NEURODEGENERATIVE DISORDERS

\section{Blocking a path to cell death}

Necrotic cell death - often considered to be a 'passive' process - has drawn much less attention in recent years than its cousin, the programmed cell death process known as apoptosis. However, Degterev and colleagues have discovered a chemical that can specifically inhibit necrotic processes. They use this inhibitor to provide evidence for a non-apoptotic cell death pathway, which they call 'necroptosis'.

Both necrosis and apoptosis can be induced by the activation of a family of 'death receptors'. Blocking the activation of caspases prevents the induction of apoptosis by death receptors, but not that of necrosis. The authors screened $\sim 15,000$ chemical compounds for one that could prevent the induction of cell death by death receptors, even in the presence of caspase inhibitors, and found one, which they dubbed necrostatin-1 (Nec-1).

This small-molecule inhibitor, whose target is currently unknown, was able to prevent the necrotic cell death induced by death receptor activation in many cell types, although it had no effect on the induction of apoptosis. This provides strong evidence that necroptosis is a common, non-apoptotic cell death pathway.

The authors also used $\mathrm{Nec}-1$ to investigate the pathological importance of necroptosis in ischaemic brain injury. In a model of brain ischaemia that involves occluding the middle cerebral artery in mice,

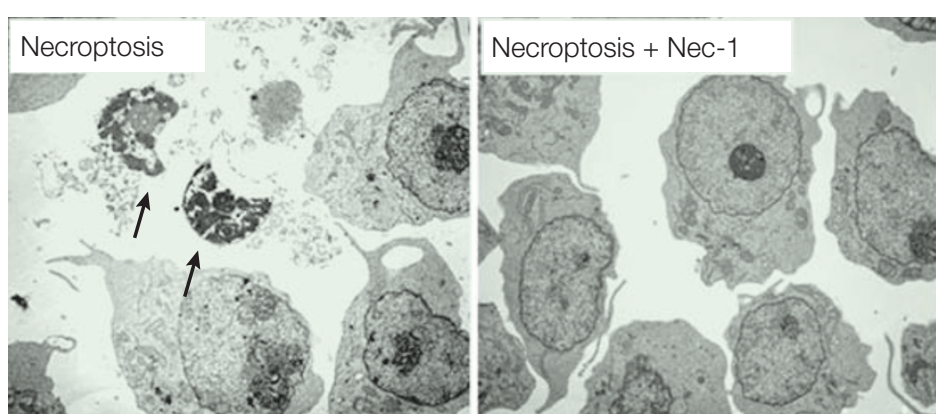

Inhibition of necroptosis by necrostatin-1 (Nec-1). Representative electron micrographs of the effect of $30 \mu \mathrm{M} \mathrm{Nec}-1$ on necroptotic Fas-associated death domain (FADD)-deficient Jurkat cells treated with $10 \mathrm{ng} \mathrm{ml}^{-1}$ human tumour necrosis factor- $\alpha(T N F \alpha)$ for $6 \mathrm{~h}$. Magnification is $\times 15,000$. Arrows indicate dead cells. Image courtesy of J. Yuan, Harvard Medical School, Boston, Massachusetts, USA.

\section{IN BRIEF}

\section{EPIGENETICS}

XIr3b is a new imprinted candidate for X-linked parentof-origin effects on cognitive function in mice.

Davies, W. et al. Nature Genet. 37, 625-629 (2005)

Identification of a cluster of $X$-linked imprinted genes in mice.

Raefski, A. S. \& O’Neill, M. J. Nature Genet. 37, 620-624 (2005)

Epigenetic modification of genes results in differential expression between maternal and paternal alleles, which is responsible for 'parent-of-origin' effects on phenotypic traits. Two new studies have identified $X l r 3 b$ as a novel X-linked imprinted gene that is associated with cognitive function. Davies et al. used a 39,XO mouse model, which is free of mosaicism and therefore allows the researchers to attribute phenotypic differences between female progenies $-39, \mathrm{X}^{\mathrm{m}} \mathrm{O}$ or $39, \mathrm{X}^{\mathrm{P} O}$ - to the parental origin of the $\mathrm{X}$ chromosome. They confirmed the existence of X-linked imprinted effects on cognitive function and, by comparing gene expression in brain samples from $39, \mathrm{X}^{\mathrm{m}} \mathrm{O}$ and $39, \mathrm{X}^{\mathrm{P} O}$ embryos, they identified a maternally expressed imprinted gene candidate on the X chromosome, Xlr3b. Raefski and O'Neill carried out comparative transcriptome analysis in a mouse model of Turner syndrome, and identified a cluster of X-linked genes that contains at least three genes $-X l r 3 b, X l r 4 b$ and $X l r 4 c$ - that show transcriptional repression of paternal alleles.

\section{ADDICTION}

Regulation of gene expression by chronic morphine and morphine withdrawal in the locus ceruleus and ventral tegmental area.

McClung, C. A. et al. J. Neurosci. 25, 6005-6015 (2005)

The different behavioural effects of morphine are mediated by different brain regions, such as the locus coeruleus, which is involved in physical dependence and withdrawal, and the ventral tegmental area, which contributes to reward and locomotor responses to the drug. By using DNA microarray analysis, McClung and colleagues identified several gene expression changes associated with drug administration and/or withdrawal in these brain regions. Inhibition of two of these gene products, prodynorpin and FK506-binding protein 5, had profound effects on withdrawal responses.

\section{VISION}

Function of a fly motion-sensitive neuron matches eye movements during free flight.

Kern, R. et al. PLoS Biol. 3, e171 (2005)

Images moving across the eye - known as optic flow - provide sensory information to neurons to guide behaviours such as avoidance and predation. Kern et al. employed an ingenious 'panoramic virtual reality stimulator' to analyse the optic flow in a blowfly. They found that motion-sensitive equatorial neurons in the horizontal system could extract information about the spatial layout of the environment by using intervals of stable vision that result from the saccadic viewing strategy. 